\title{
Evaluation of German Cockroach, Blattella germanica from Different Niches for Bacterial Contamination
}

\author{
Ekong Mercy Okon*, Tarh Jacqueline Ebob, Iroegbu Christian Ukwuoma \\ Department of Microbiology, Faculty of Biological Sciences, Cross River University of Technology, Calabar, Nigeria \\ Email address: \\ ekongmercy1@gmail.com (E. M. Okon),j.ebobtarh@yahoo.com (T. J. Ebob), chrisuiroegbu@yahoo.com (I. C. Ukwuoma) \\ ${ }^{*}$ Corresponding author
}

\section{To cite this article:}

Ekong Mercy Okon, Tarh Jacqueline Ebob, Iroegbu Christian Ukwuoma. Evaluation of German Cockroach, Blattella germanica from Different Niches for Bacterial Contamination. American Journal of Bioscience and Bioengineering. Vol. 8, No. 3, 2020, pp. 41-45. doi: 10.11648/j.bio.20200803.12

Received: February 14, 2020; Accepted: February 28, 2020; Published: June 20, 2020

\begin{abstract}
Cohabitating nature of cockroach with humans is on the increase in most rural and underdeveloped areas of Cross River State including Calabar South. It is therefore important to screen the bacterial carriage of this pest because of shared ecological niche. Sticky trap method was used to capture the pest and properly identify by an Entomologist Dr Ogban, Cross River University of Technology, Calabar. They were killed using chloroform. Pour plating culturing technique was used for bacterial isolation, isolates were characterized and identified using standard bacteriological methods. The research result reveals eleven (11) bacterial species (Bacillus, Klebsiella, E. coli, P. aeruginosa, S. aureus, Proteus, S. epidermidis, Streptococcus, Salmonella, Shigella and Enterococcus). E. coli Klebsiella and Bacillus were the most frequently isolated organisms from the external surface of latrines and living house cockroaches. Klebsiella, E. coli and Enterococcus species were predominant in the gastrointestinal tract (GIT) of cockroaches from same ecological niche except that in living houses, the presence of Enterococcus species were insignificance compare to other isolates. There was a significant difference at $P$ $=.05$ in isolates from cockroaches captured from latrines area to those from living houses. The degree of contamination based on sum total of each isolate from External and GIT parts of cockroaches from both experimental niche was; E. coli $>$ Klebsiella $>$ S. aureus $>$ Bacillus $>$ Shigella $>$ P. aeruginosa $=$ Samonella $=$ Enterococcus $>$ Streptococcus $>$ S. epidermidis $>$ Proteus. This study encourages the use of some natural and home friendly cockroach eradication techniques that pose no harm to home dwellers and it environ. This include timely removal of bushes around the living environ, frequent sealing of cracks around the kitchens, and bathrooms to reduce potential hidings areas. Getting rids of all foods remains on kitchen tables, floor etc. Application of boil mint leaves at different corners of the house. These will naturally scare the presence of this pest from human habitation and serve as a better strategy to minimize cockroach-associated infections.
\end{abstract}

Keywords: Cockroach, External Body Surface, Gastrointestinal Tract (GIT), Latrines, Living Houses, E. coli, Klebsiella and Bacillus Species

\section{Introduction}

There are over 4,600 known species of cockroach of which 30 are associated with human habitations. Their apparent ubiquity stems from their special ability to tolerate a wide range of environmental conditions ranging from cold to tropical heat [1]. Some of the most common species include German cockroach (B. germanica), American cockroach (Periplaneta americana), brown-banded cockroaches (Supella longipalpa) and Oriental cockroaches (Blatta orientalis). B. germanica is the most important and most common species of cockroach found everywhere in the world [2]. They have special preference for starchy, sugary and fermented foods. They sometimes feed on dead or wounded cockroaches of their own or other species. Cockroaches are commonly found around hospitals, sick rooms, areas of intensive care, surgical sections, living rooms, toilet areas etc. and are presumed to play a pivotal role in diseases transmission and are, therefore, threat to public health [3]. They are presumed to harbor pathogenic organisms such as Bacillus, Salmonella, Escherichia coli, Listeria monocytogenes, Enterococcus faecalis, Aspergillus niger, although the distributions of these 
organisms to disease causation differ depending on location, environmental and sanitary conditions [4]. Hence, this research reports the evaluation of B. germanica samples trapped from different ecological niches in Calabar South Local Government Area of Cross River State for bacterial contamination.

\section{Materials and Methods}

\subsection{Study Area}

The study was carried out between March and April, 2019 in Calabar South, Cross River State. The area was chosen because of the low sanitary condition such as unkempt bushes, heaps of refuse etc. serving as a conducive environment for proliferation of different insects such as housefly, blackfly, cockroaches among others. Some houses in this area are still making use of pit latrines, few houses that make use of water closet are unable to keep them in good condition because of non-availability or irregular supply of water. This area has mean annual rain fall of $1830 \mathrm{~mm}$ and two distinct seasons; the rainy season (April-September) and dry season (October-March).

\subsection{Sample Collection}

Altogether, 80 adult cockroaches were randomly trapped at night using stick trap, 40 from toilets and 40 from living houses. Each sample was placed in a universal bottle and transported immediately to Microbiology Laboratory, Cross River University of Technology for analysis. Trapped samples (Cockroaches) were killed using chloroform and examined under a dissecting microscope for affirmation of identity using standard taxonomy keys.

\subsection{Bacterial Cell Count, Isolation and Characterization of Bacterial Species}

Each cockroach was taken with sterile forceps and put into $10 \mathrm{~mL}$ of sterile saline in a universal bottle. After closing the bottle with a screw cap, it was vortexed several times to wash free the microbial contaminants on the external surface. Approximately $1.0 \mathrm{~mL}$ of the wash-saline was added to $9.0 \mathrm{~mL}$ of sterile saline to get a $10^{-1}$ dilution. This was serially diluted ten-fold down to $10^{-10}$. A $1.0 \mathrm{~mL}$ inoculum was taken and plated simultaneously in nutrient agar (NA) and MacConkey agar (MA) respectively. After incubation for 24 hours in a humidified incubator, the plates were examined and the bacterial colonies counted. Subsequently, plates with well separated colonies were taken and discrete colonies isolated. Each colony was purified by streaking and re-isolating three successive times in agar. Purified colonies were then characterised using standard bacteriological techniques. This technique was used to determine the contamination of the external surfaces. Thereafter, the cockroach was placed in $70 \%$ ethanol to decontaminate the external surface. Then it was rinsed in distilled water and allowed to dry at room temperature. The cockroach was aseptically dissected to remove the gastrointestinal tract (GIT) using sterile forceps, scalpels and scissors. The contamination of the GIT was done by homogenizing the gut and other abdominal organs in a sintered glass tissue grinder. A $1.0 \mathrm{~g}$ amount of the homogenised tissue was suspended in $9.0 \mathrm{~mL}$ of saline and the suspension serially diluted ten-fold. Each dilution was plated simultaneously in NA and MA as earlier described.

\subsection{Data Analysis}

SPSS version 20 was used for descriptive statistics. The student Unpaired T-test compared the means value of isolates from different parts of the sample. ANNOVA compared the significant difference at $P=.05$ between isolates from different ecological niche.

\section{Results}

Table 1. Bacterial Isolates Identified from External and GIT of B. germanica.

\begin{tabular}{lllll}
\hline \multirow{2}{*}{ Bacterial Isolate } & \multicolumn{2}{l}{ External Surface } & GIT & \\
\cline { 2 - 5 } & Latrines & L. Room & Latrines & L. Room \\
\hline Bacillus Sp & 5 & 4 & 3 & 1 \\
Klebsiella Sp & 7 & 6 & 9 & 5 \\
E. coli Sp & 8 & 7 & 7 & 6 \\
P. aeruginosa & 4 & 3 & 1 & 0 \\
S. aureus & 3 & 3 & 4 & 4 \\
Proteus Sp & 1 & 1 & 0 & 0 \\
S. epidermidis & 1 & 2 & 0 & 0 \\
Streptococcus Sp & 1 & 2 & 1 & 1 \\
Salmonella Sp & 2 & 2 & 2 & 2 \\
Shigella Sp & 1 & 2 & 2 & 4 \\
Enterococcus Sp & 0 & 0 & 5 & 3 \\
Total & 33 & 32 & 34 & 26 \\
\hline
\end{tabular}

E. coli $=$ Escherichia coli, $\mathrm{P}$. aeruginosa $=$ Pseudomonas aeruginosa, $\mathrm{S}$. aureus $=$ Staphylococcus aureus, S. epidermidis = Staphylococcus epidermidis, GIT = Gastro-intestinal tract, L. Room = Living Room

Evaluation of external and GIT of cockroaches captured from latrines and living houses reveal 11 genera of bacteria identified as Bacillus, Klebsiella, E. coli, P. aeruginosa, S. aureus, Proteus, S. epidermidis, Streptococcus, Salmonella, Shigella and Enterococcus species respectively.

With reference to cockroaches caught from latrines, E. coli species was the most frequently isolated flora, isolated 8 times out of 33 samples. This was followed by Klebsiella, Bacillus, Pseudomonas, S. aureus, Salmonella, Proteus, S. epidermidis, Streptococcus, Shigella species with the respective rates of isolation shown in Table 1 . Of the 32 cockroach samples caught in the living houses, 7 yielded $\mathrm{E}$ coli and Klebsiella (6), Bacillus (4), Pseudomonas and Staphylococcus (3 each); S. epidermidis, Streptococcus, Salmonella and Shigella (2, each); and Proteus species (1) (Table 1). There was a significant difference at $\mathrm{P}=.05$ in isolates caught from latrines area to those from living houses.

\subsection{Bacterial Contaminants from External Surface of Cockroaches Caught from Latrines and Living Houses}

The external surface of cockroaches from latrines yielded $E$. coli as the highest isolated organism found in 8 
samples (24\%). This was followed by Klebsiella, Bacillus, $P$ aeruginosa and Staphylococcus aureus with isolation rate of $21,15,12$ and $10 \%$ respectively. Salmonella was isolated in 2 (7\%) cockroach sample. Proteus, S. epidermidis, Streptococcus, and Shigella occurred just once (3\%). Enterococcus species was not found among these group of samples. E. coli was also the most frequently isolated 7 (22\%) among samples obtained from living houses followed by Klebsiella 6 (19\%), Bacillus 4 (13\%). P. aeruginosa and S. aureus occurred in $3(9 \%)$ samples each, S. epidermidis, Streptococcus, Salmonella and Shigella species occurred in $2(6 \%)$ samples each, Enterococcus was not among the isolates obtained from living houses (Figure 1).

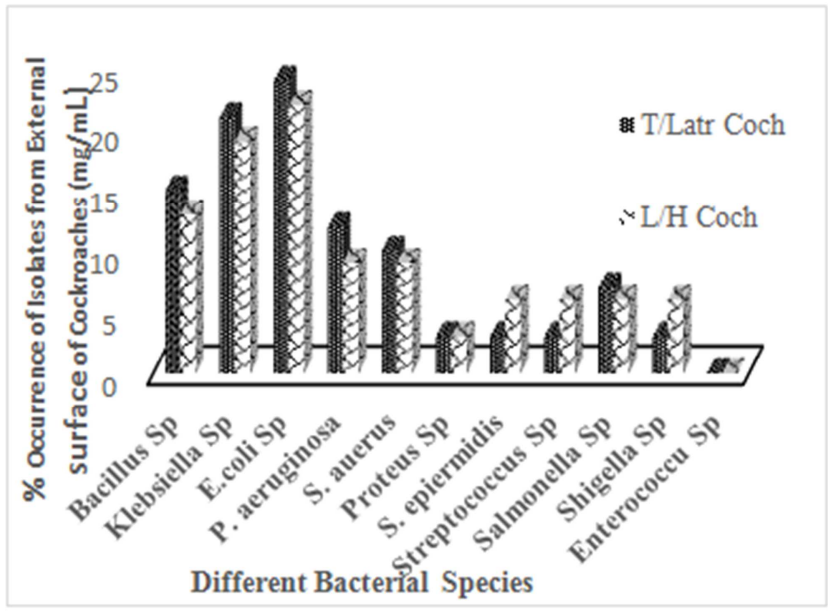

Figure 1. Showing the Distribution of Different Bacterial species from External surface of Cockroaches captured from Toilet/latrines and Living Houses.

\subsection{Frequency of Isolation of Bacterial Contaminants from the GIT of Cockroaches Obtained from Latrines and Living Houses}

Among the bacteria genera isolated from the GIT of cockroaches obtained from latrines, Klebsiella species occurred in 9 out of 34 specimens (27\%) followed by $E$. coli, Enterobacter and Staphylococcus species with 21, 15 and $12 \%$ occurrence respectively. Bacillus occurred in 3 cockroach samples (9\%) while Shigella and Salmonella species occurred in $2(6 \%)$ each and Pseudomonas, Streptococcus and Salmonella species in $1(3 \%)$ each. For cockroaches captured from living houses, E. coli showed the highest occurrence (23\%) followed by Klebsiella (19\%), and Staphylococcus and Shigella species (15\% each), Enterobacter species occurred in 3 (12\%) cockroach samples, Salmonella species in $2(8 \%)$, while Bacillus and Streptococcus species occurred in 1 (4\%) each. Pseudomonas $\mathrm{S} p$ was not isolated from the GIT of this group of cockroaches (Figure 2).

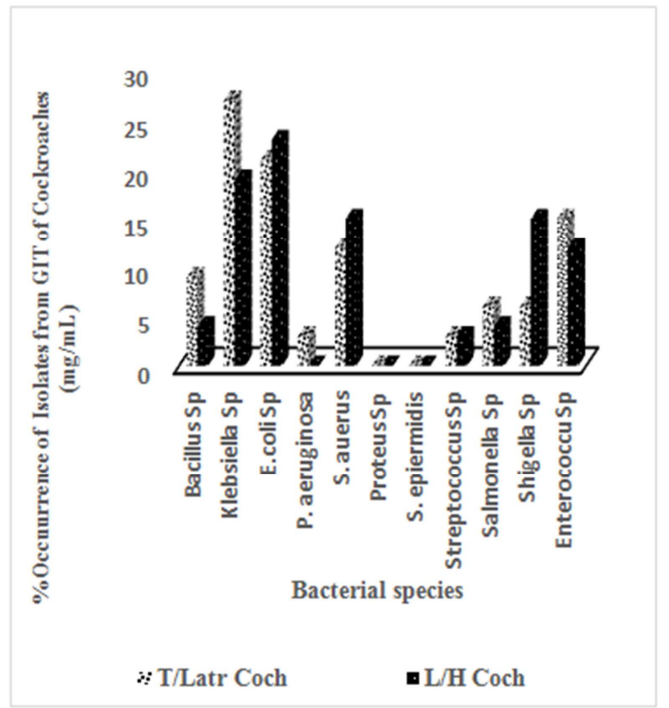

Figure 2. Showing the Distribution of Different Bacterial species from GIT of Cockroaches captured from Toilet/latrines and Living Houses.

\subsection{Total Number of Bacterial Isolates from Cockroaches According to Body part (External and GIT) and Source (latrines and living houses)}

Of 65 cockroach samples captured, 33 from latrines and 32 from living houses, E. coli yielded the highest 15 (23\%) from external surface of cockroaches, this was followed by Klebsiella $13(20 \%)$, Bacillus 9 (14\%) P. aeruginosa 7 (11\%), S. aureus 6 $(9 \%)$, Salmonella 4 (16\%). S epidermidis, Streptococcus and Shigella species had a total occurrence of $3(5 \%)$ each, Proteus was the least with occurrence rate of $2(3 \%)$.

The internal part (GIT) of sixty (60) cockroach samples were analysed, $14(23 \%)$ was Klebsiella, $13(22 \%)$ was E. coli. $8(13 \%)$ was from S. aureus and Shigella, $6(10 \%)$ came from Salmonella, 2 (3.3\%) came from Streptococcus. P. aeruginosa was the least isolate $1(1.7 \%)$, Proteus and S. epidermidis were not isolated from this group of sample (Figures 3 and 4).

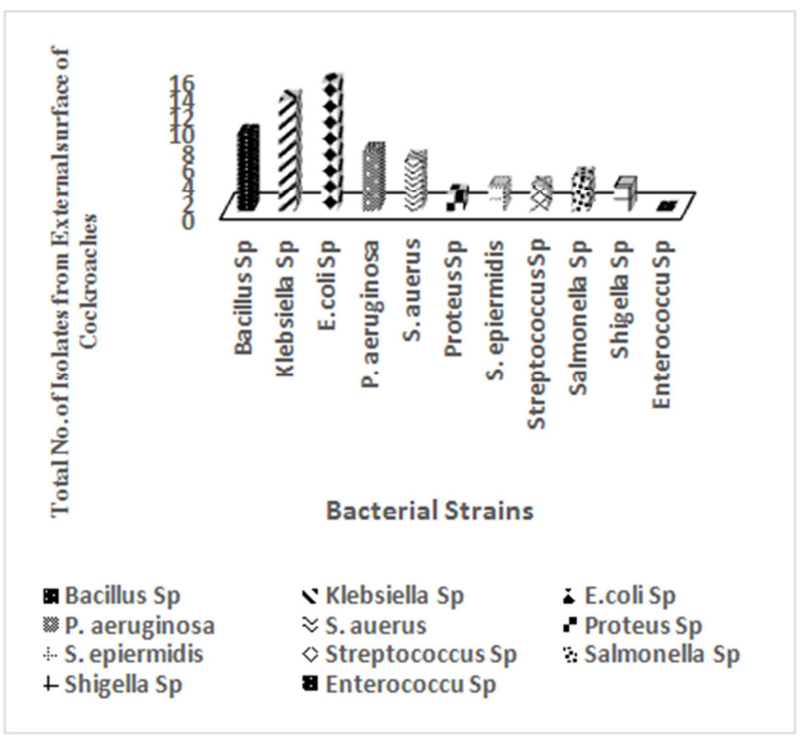

Figure 3. Total number of Each Isolate from External Surface of Cockroaches Captured from Latrines and Living Houses. 


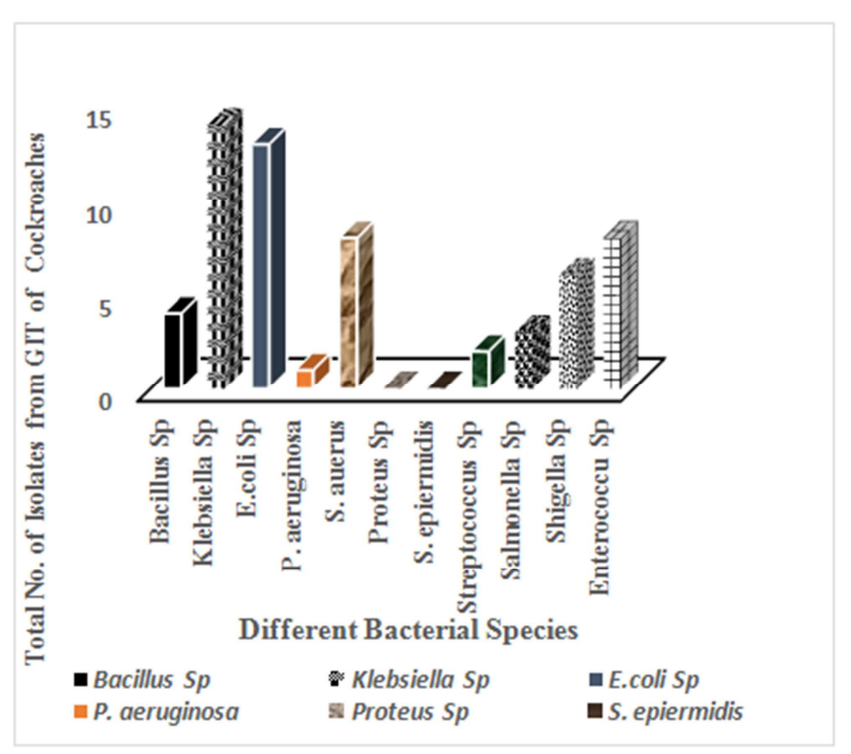

Figure 4. Total number of Each Isolate from GIT of Cockroaches Captured from Latrines and Living Houses.

The degree of contamination based on sum total of each isolate from External and Internal (GIT) parts of cockroaches from both experimental sources was; E. coli $>$ Klebsiella $>$ S. aureus $>$ Bacillus $>$ Shigella $>$ P. aeruginosa $=$ Samonella $=$ Enterococcus $>$ Streptococcus $>$ S. epidermidis $>$ Proteus (Figure 5).

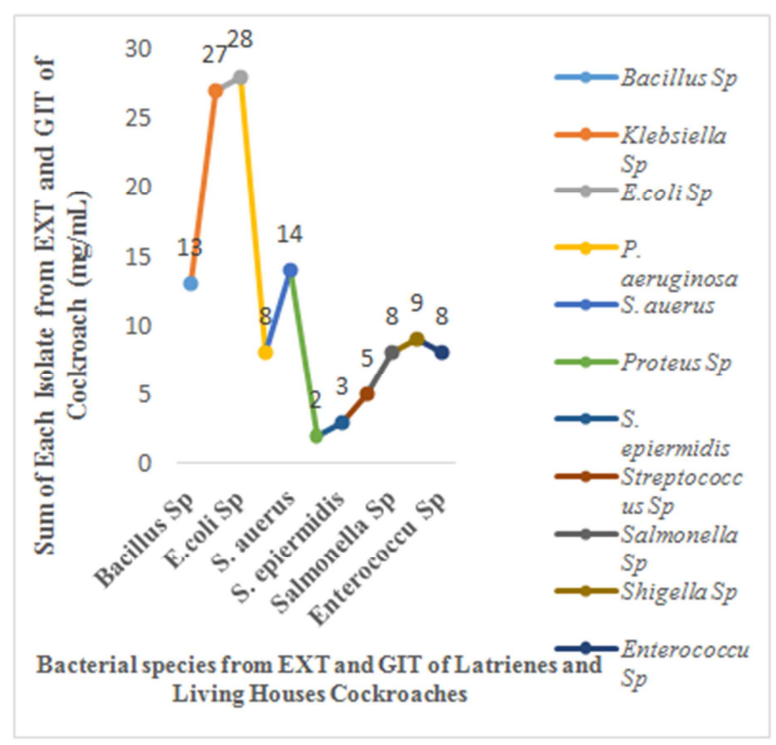

Figure 5. Showing sum total of Each Bacterial Isolates from External and GIT of cockroaches captured from latrines and Living Houses.

Key

$\mathrm{EXT}=$ External

$\mathrm{GIT}=$ Gastrointestinal tract

\section{Discussion}

Cockroaches are commonly seen in many human habitations, particularly in kitchens where foods are stored, processed, prepared, or served as well as around latrines in contact with human faeces and everywhere in the hospital environment [5]. They are ubiquitous and possess nocturnal and omnivorous attributes that make them mechanical transmitters of pathogenic organisms including bacteria, fungi, parasites and viruses [6, 7].

The evaluation of $B$. germanica from different niches for bacterial contamination was conducted on 80 cockroach samples captured from latrines and living houses in Calabar South, Cross River State, Nigeria. Eleven bacterial genera (Bacillus, Klebsiella, E. coli, P. aeruginosa, S. aureus, Proteus, S. epidermidis, Streptococcus, Salmonella, Shigella and Enterococcus species) were isolated and identified using standard bacteriological techniques.

Cockroaches caught from latrines showed high occurrence of E. coli species, isolated 8 times out of 33 samples, followed by Klebsiella, Bacillus, Pseudomonas, S. aureus, Salmonella, Proteus, S. epidermidis, Streptococcus and Shigella species with the respective rates of isolation shown in Table 1. Of the 32 cockroach samples caught in the living houses, E coli were found in 7 samples and Klebsiella (6), Bacillus (4), Pseudomonas and Staphylococcus (3 each); S. epidermidis, Streptococcus, Salmonella and Shigella (2, each); and Proteus species (1).

E. coli, Klebsiella and Bacillus species were the highest contaminant of the external surface of cockroaches captured from latrines and living houses.

Klebsiella, E. coli and Enterococcus were the most frequent isolated organisms from the GIT of latrines. This was same for living houses except that the presence of Enterococcus was insignificant compare to the above mentioned organisms. E. coli was the leading isolate among other organisms from external surface, GIT of latrines and living houses, whereas Klebsiella was leading other isolates from GIT of latrines cockroaches respectively.

The sum total of each isolate from external and GIT of latrines and living house cockroaches reveal the level of contamination in the order of E. coli $>$ Klebsiella $>S$. aureus $>$ Bacillus $>$ Shigella $>$ P. aeruginosa $=$ Samonella $=$ Enterococcus $>$ Streptococcus $>$ S. epidermidis $>$ Proteus.

The Presence of $E$ coli outside and inside of the cockroach shows faecal contamination which is not surprising given that latrines and other dirty places are common habitats for them. On the other hand, a good number of these isolates have been associated with food borne infections and human intestinal diseases such as abdominal cramps, bloody diarrheal, vomiting, pneumonia, blood stream infection, wound infection, urinary tract infection, bacteraemia, and liver abscesses [8, 9]. Mpuchane et al. (2006) [10] had also observed these pathogens as common isolates from cockroaches trapped from kitchen and living houses in the Central/Broadhurst, Old Naledi and Tlokweng of Gaborone, Botswana. Feleke et al. (2016) [11] also reported high occurrence of Klebsiella (17.7\%), E. coli (16\%) and Citrobacter (15\%) species as leading isolates from external and internal surfaces of cockroaches found in the hospital environment; adding that $E$. coli was also the predominant isolate from nonhospital cockroaches. 
The presence of Enterobacter $\mathrm{Sp}$ and absence of $S$. epidermidis from the internal GIT of cockroaches has not been reported by other worker and may reflect differences in cockroach species and locations in which cockroaches were trapped.

The presence of cockroach in human habitation is a serious public health problem. Thus, regular control of this pest by strict implementation of pest control regulations is of primary importance for the safety of public health.

\section{Conclusion}

Different bacteria species were isolated from cockroaches trapped from different ecological niches. $E$. coli, Klebsiella and Bacillus were the principal isolates from both external and GIT part of cockroaches except that Enterococcus species replaces Bacillus in GIT. These pathogens are threat to human health as they are major causative agents of human intestinal diseases, blood and organ infection. This research advocates the use of natural/harmless cockroach eradicative measures at homes with high population of children. These include routine removal of bushes around the living environ, frequent sealing of cracks around the kitchens, and bathrooms to reduce potential hidings areas. Getting rids of all foods remains on kitchen tables, floor etc. Application of boil mint leaves at different corners of the house. These will naturally scare the presence of this pest from human habitation and serve as a better strategy to minimize cockroach-associated infections.

\section{Consent}

It is not applicable.

\section{Ethical Approval}

It is not applicable.

\section{Acknowledgements}

Sincere appreciation goes to my supervisor Prof. C. U. Iroegbu for scientific contribution. Many thanks to the people of Calabar South who open their doors during sample collection and Mrs. Tarh, Jacqueline Ebob for providing some laboratory equipment that were needed for successful completion of this research.

\section{References}

[1] Mohs, K, McGee, I (2007). Animal Planet: the most extreme bugs (Ist Edition), John Wiley and Sons. P. 35.

[2] Hassan, N (2010). An Overview of German cockroach, Blattella germanica, Studies Conducted in Iran. Pakistan. Journal of Biological Sciences. 13 (22): 1077-1084.

[3] Taha, M., Fatima, M., Souad, EI- h., Samir, T., Rochdi, M., and Haroun, C (2014). Bacterial load of German cockroach (Blattella germanica) found in hospital environment. Pathology Global Health. 108 (3): 141-147.

[4] Isaac, C., Orue, P. O., Inyamu, M. I., Ehiaghe, J. I., and Isaac, O. (2014). Comparative Analysis of Pathogenic Organisms in Cockroaches from Different Community Settings in Edo State, Nigeria, Korean J. of Parasitology. 52 (2): 177-181.

[5] Fakoorziba, M. R., Eghbal, F., Hassanzadeh, J., Moemenbellah-Fard, M. D. (2010). Cockroaches (Periplaneta americana and Blattella germanica) as potential vectors of the pathogenic bacteria found in nosocomial infections. Annual Tropical Medical Parasitology. 104 (6): 521-8.

[6] Tatfeng, Y. M., Usuanlele, M. U., Orukpe, A., Digban, A. K., Okodua, M., Oviasogie, F., Turay, A. A. (2005). Mechanical transmission of pathogenic organisms: the role of cockroaches. J. Vector Borne Diseases. 42 (4): 129-34.

[7] Salehzadeh, A., Tavacol, P., Mahjub, H. (2007). Bacterial, fungal and parasitic contamination of cockroaches in public hospitals of Hamadan, Iran. Journal Vector Borne Diseases. 44 (2): 105-10.

[8] Vila, J. E., Sáez-López, J. R., Johnson, U., Römling, U., Dobrindt, R., Cantón, C. G., Giske, T., Naas, A. (2016). Carattoli M, Martínez M. Escherichia coli: an old friend with new tidings, FEMS Microbiol. Reviews, 40 (4) 437- 463.

[9] Michelle, K., Paczosa, J. M. (2016). Klebsiella pneumoniae: Going on the Offense with a Strong Defense. Microbiol. and Molecul. Biology Review. 00078-15.

[10] Mpuchane, S., Allorey, J., Marsheka, I., Simpanya, M., Coetzee, S., Jordaan, A., Mrema, N.. and Gashe, B. A. (2006). Carriage of Microorganisms by domestic cockroaches and implications on food safety. AJFAND. 26 (3) 166-175.

[11] Feleke, M., Setegn, E., Mengistu, E., Kahsay, H., Dagnachew, M., Tigist, F., Fisha, G. S., Getenet, A., and Raja, N. (2016). Cockroaches as a Source of High Bacterial Pathogens with Multidrug Resistant Strains in Gondar Town, Ethiopia. Biomedical Research International. 2825056. 